Pacific Journal of Mathematics

GROUPS OF ARITHMETIC FUNCTIONS UNDER DIRICHLET 


\title{
GROUPS OF ARITHMETIC FUNCTIONS UNDER DIRICHLET CONVOLUTION
}

\author{
ROY W. RYDEN
}

If $f$ is an arithmetic function, let $T(f)=\{(a, b) \mid f(a b)=$ $f(a) f(b)\}$. If $S$ is a set of pairs of positive integers, let $f \in M(S)$ if $T(f) \supseteq S$. In this paper we determine all sets $S$ such that $M(S)$ is a group under Dirichlet convolution.

1. Introduction. An arithmetic function $f$ is a complex-valued function whose domain is the set $N=\{1,2,3, \cdots\}$. The multiplicative set belonging to $f$ is the set $T(f)=\{(a, b) \mid f(a b)=f(a) f(b)\}$. If $S$ is any nonempty subset of $N \times N$, then we say that $f \in M(S)$ if $f \neq 0$ and $T(f) \supseteqq S$. We shall let $\mathscr{R}$ denote the set $\{(a, b) \mid G C D(a, b)=1\}$. Furthermore, for convenience we shall assume that all of our sets $S \subseteq N \times N$ are symmetric $\cdots(a, b) \in S$ if and only if $(b, a) \in S$.

It is well-known (see [1]) that $M(\mathscr{R})$, the set of all multiplicative functions, forms an Abelian group under the Dirichlet convolution

$$
\left[f^{*} g\right](n)=\sum_{d \backslash n} f(d) g(n / d) \text {. }
$$

In this paper we intend to characterize completely all those sets $S$ such that $M(S)$ is a group under*. It is not hard to show that all of our results carry through for the generalized convolution defined by Goldsmith [2]. We shall work with* for simplicity.

Some of the contents of this paper appeared in the author's Ph.D. thesis written at the University of Oregon under the direction of Professor Ivan Niven.

2. The multiplicative closure of a set. It is convenient for us to introduce a closure operation on subsets of $N \times N$. Properties of this operation which are not necessary for this paper will be discussed by the author elsewhere.

If $S \subseteq N \times N$, then the transformation

$$
\left(a_{1}, a_{2}, \cdots, a_{n}\right) \longleftrightarrow\left(b_{1}, b_{2}, \cdots, b_{n}, b_{n+1}\right)
$$

is said to be an S-step if

$$
a_{j}=b_{j}
$$$$
\text { for } j=1,2, \cdots, n-1
$$

$$
a_{n}=b_{n} b_{n+1}
$$

and

$$
\left(b_{n}, b_{n+1}\right) \in S \text {, }
$$


where all $n$-tuples for $n \geqq 3$ are to be considered as unordered. It should be emphasized that an $S$-step is a transformation which can go either from $\left(a_{1}, a_{2}, \cdots, a_{n}\right)$ to $\left(b_{1}, b_{2}, \cdots, b_{n}, b_{n+1}\right)$, or from $\left(b_{1}, b_{2}, \cdots\right.$, $\left.b_{n}, b_{n+1}\right)$ to $\left(a_{1}, a_{2}, \cdots, a_{n}\right)$. An $S$-chain is any sequence of $S$-steps. We say that a pair $(a, b)$ is in $S^{*}$, the multiplicative closure of $S$, if there exists a finite $S$-chain leading from the 1-tuple $(a b)$ to the pair $(a, b)$. A set $S$ is closed if $S=S^{*}$.

THEOREM 2.1. (i ) $S \subseteq S^{*}$, and $A \subseteq B$ implies $A^{*} \subseteq B^{*}$;

(ii) $S^{* *}=S^{*}$;

(iii) $T(f)$ is closed for all functions $f$.

Proof. (i) Notice that $\left(a_{1} a_{2}\right) \rightarrow\left(a_{1}, a_{2}\right)$ is an $S$-chain if $(a, b) \in S$. To see that (ii) holds, let $\left(a_{1}, \cdots, a_{n}\right) \leftrightarrow\left(b_{1}, \cdots, b_{n}, b_{n+1}\right)$ be an $S^{*}$-step where $a_{i}=b_{i}$ for $i=1,2, \cdots, n-1, b_{n} b_{n+1}=a_{n}$ and $\left(b_{n}, b_{n+1}\right) \in S^{*}$. Then there exists a finite $S$-chain:

$$
\left(b_{n} b_{n+1}\right) \longrightarrow\left(c_{1}, c_{2}\right) \longrightarrow \cdots \longrightarrow\left(d_{1}, d_{2}, d_{3}\right) \longrightarrow\left(b_{n}, b_{n+1}\right) \text {. }
$$

Notice that the following is a finite S-chain:

$$
\begin{aligned}
\left(a_{1}, \cdots, a_{n}\right) & \longrightarrow\left(a_{1}, \cdots, a_{n-1}, c_{1}, c_{2}\right) \\
& =\left(b_{1}, b_{2}, \cdots, b_{n-1}, c_{1}, c_{2}\right) \\
& \longrightarrow \cdots \\
& \longrightarrow\left(b_{1}, \cdots, b_{n-1}, d_{1}, d_{2}, d_{3}\right) \\
& \longrightarrow\left(b_{1}, \cdots, b_{n-1}, b_{n}, b_{n+1}\right) .
\end{aligned}
$$

Hence any finite $S^{*}$-chain can be represented as a finite $S$-chain and (ii) follows.

To prove (iii), if $(n m) \rightarrow\left(n_{1}, n_{2}\right) \rightarrow \cdots \rightarrow\left(b_{1}, b_{2}, m\right) \rightarrow(n, m)$ is a $T(f)$-chain, then

$$
\begin{aligned}
f(n m) & =f\left(n_{1}\right) f\left(n_{2}\right) \\
& =\cdots \\
& =f\left(b_{1}\right) f\left(b_{2}\right) f(m) \\
& =f(n) f(m),
\end{aligned}
$$

so that $(n, m) \in T(f)^{*}$ implies that $(n, m) \in T(f)$.

If $\varphi$ is Euler's totient function, then it is not hard to see that $T(\varphi)=\mathscr{R}$. Hence we can conclude from 2.1 that the set $\mathscr{R}$ is closed.

A set $S$ is divisible if $(a, b) \in S$ implies that $\left(d, d^{\prime}\right) \in S$ whenever $d \mid a$ and $d^{\prime} \mid b$. Notice that $\mathscr{R}$ is a divisible set.

THEOREM 2.2. If $S$ is a divisible subset of $\mathscr{R}$, then $S^{*}$ is also 
a divisible subset of $\mathscr{R}$.

Proof. The fact that $S^{*} \subseteq \mathscr{R}$ is immediate because $\mathscr{R}$ is closed. If $(a, b) \in S^{*}$ and $p^{\alpha} \| a$ and $q^{\beta} \| b$ where $p$ and $q$ are primes, then $\left(p^{\alpha}, q^{\beta}\right) \in S$. If not, then $\left(p^{\alpha} x, q^{\beta} y\right) \notin S$ by the divisibility of $S$ so that if $(a b) \rightarrow(u, v) \rightarrow \cdots \rightarrow(a, b)$ is an $S$-chain then one and only one "co-ordinate" of each-tuple involved must be divisible by $p^{\alpha} q^{\beta}$. But this is a contradiction because $p^{\alpha} \mid a$ and $q^{\beta} \mid b$. Therefore $\left(p^{i}, q^{i}\right) \in S$ for all $i \leqq \alpha, j \leqq \beta$, by the divisibility of $S$.

Assume that $d\left|a, d^{\prime}\right| b$, and $\left(\delta, \delta^{\prime}\right) \in S^{*}$ for all $\delta\left|d, \delta^{\prime}\right| d^{\prime}$, and $\left(\delta, \delta^{\prime}\right) \neq\left(d, d^{\prime}\right)$. Since $(a, b) \in S^{*}$ let $(a b) \rightarrow(u, v)$ be a first $S$-step where $(u, v) \in S, u=d_{1} d_{1}^{\prime} d_{1}^{\prime \prime}, v=d_{2} d_{2}^{\prime} d_{2}^{\prime \prime}, d_{1} d_{2}=d$, and $d_{1}^{\prime} d_{2}^{\prime}=d^{\prime}$. By the divisibility of $S$ we have $\left(d_{1} d_{1}^{\prime}, d_{2} d_{2}^{\prime}\right) \in S,\left(d_{1}, d_{2}\right) \in S$, and $\left(d_{1}^{\prime}, d_{2}^{\prime}\right) \in S$. By the choice of $\left(d, d^{\prime}\right)$ we have $\left(d_{1}, d_{1}^{\prime}\right)$ and $\left(d_{2}, d_{2}^{\prime}\right) \in S^{*}$. Hence the following S-chain obtains:

$$
\begin{aligned}
\left(d d^{\prime}\right)=\left(d_{1} d_{1}^{\prime} d_{2} d_{2}^{\prime}\right) & \longrightarrow\left(d_{1} d_{1}^{\prime}, d_{2} d_{2}^{\prime}\right) \\
& \longrightarrow\left(d_{1}, d_{1}^{\prime}, d_{2} d_{2}^{\prime}\right) \\
& \longrightarrow\left(d_{1}, d_{1}^{\prime}, d_{2}, d_{2}^{\prime}\right) \\
& \longrightarrow\left(d_{1} d_{2}, d_{2} d_{2}^{\prime}\right) \\
& \longrightarrow\left(d, d^{\prime}\right)
\end{aligned}
$$

so that $\left(d, d^{\prime}\right) \in S^{*}$.

3. The main results. A set $S$ is said to have property $P$ if $f^{*} g \in M(S)$ whenever $f$ and $g$ are in $M(S)$. The main theorem of this paper is the following characterization.

Theorem 3.1. A set $S$ has property $P$ if, and only if $S^{*}$ is a divisible subset of $\mathscr{R}$. In particular, all divisible subsets of $\mathscr{R}$ have property $P$.

The proof of Theorem 3.1 will follow from a sequence of lemmas. A set $S$ has property $P^{\prime}$ if $f^{*} 1 \in M(S)$ whenever $f \in M(S)$ where 1 is the function with constant value 1 .

Lemma 3.2. If $S$ has property $P$, then $S$ has property $P^{\prime}$.

Lemma 3.3. If $S$ has property $P^{\prime}$, then $S \subseteq \mathscr{R}$.

Proof. $1^{*} 1$ is the number of divisors function $\tau$, and it is easy to see that $T(\tau)=\mathscr{R}$. Therefore $\tau \in M(S)$ implies $\mathscr{R}=T(\tau) \supseteqq S$.

Lemma 3.4. If $S$ has property $P^{\prime}$, then $(1,1) \in S$. 
Proof. If $(1,1) \notin S$, define $f(1)=2, f(n)=0$ for all $n>1$. Then $f \in M(S)$ but $f^{*} 1 \notin M(S)$.

LEMma 3.5. Let $S$ be closed and have property $P^{\prime}$. If $(a, b) \in S$, then $(1, d) \in S$ for all $d \mid a$ and $\left(1, d^{\prime}\right) \in S$ for all $d^{\prime} \mid b$.

Proof. Assume $(1, d) \notin S$ for $d \mid a$ and $d$ is the smallest divisor of a with this property. We may assume that $\left(\delta, \delta^{\prime}\right) \notin S$ where $\delta \delta^{\prime}=d$ and $\delta \neq 1 \neq \delta^{\prime}$, because, by the minimality of $d$, the following $S$-chain obtains:

$$
(d) \longrightarrow\left(\delta, \delta^{\prime}\right) \longrightarrow\left(1, \delta, \delta^{\prime}\right) \longrightarrow(1, d) \text {. }
$$

Since $S$ is closed, $(1, d) \in S$.

Define $f$ via $f(1)=0, f(d)=1, f(x)=0$ otherwise. It is easy to see that $f \in M(S)$ by the previous remarks, but

$$
\left[f^{*} 1\right](a b) \neq\left[f^{* 1}\right](a) \cdot\left[f^{*} 1\right](b),
$$

a contradiction.

Let $k$ be fixed and let $g$ be defined via $g(1)=1, g(k)=1$, and $g(m)=0$ otherwise. It is easy to check that $T(g)$ contains all coprime pairs except those of the form $(d, k / d)$ where $d \neq 1$ or $k$.

Lemma 3.6. If $S$ is closed and has property $P^{\prime}$, then $S$ must be divisible.

Proof. Suppose that the set

$$
\left\{(a, b) \in S \mid\left(d, d^{\prime}\right) \notin S \text { for some } d\left|a, d^{\prime}\right| b, d \neq 1 \neq d^{\prime}\right\}
$$

is nonempty, and let $(a, b)$ be an element of this set which is minimal with respect to the product $a b=n$. Also pick an appropriate $\left(d, d^{\prime}\right)$ to be minimal with respect to its product $d d^{\prime}=k$.

(1) If $\delta \mid d$ and $\delta^{\prime} \mid d^{\prime}$ and $\delta \delta^{\prime}<d d^{\prime}$, then $\delta\left|a, \delta^{\prime}\right| b$, and so $\left(\delta, \delta^{\prime}\right) \in S$.

(2) If $\left(d_{1}, d_{1}^{\prime}\right) \in S$ where $d_{1} d_{1}^{\prime}=k, d_{1} \neq 1 \neq d_{1}^{\prime}$, then $\left(\delta, \delta^{\prime}\right) \in S$ for all $\delta \mid d_{1}$ and $\delta^{\prime} \mid d_{1}^{\prime}$ by the minimality of $a b=n$.

We may assume, however, that $\left(d_{1}, d_{1}^{1}\right) \notin S$ whenever

$$
d_{1} d_{1}^{\prime}=k, d_{1} \neq 1 \neq d_{1}^{\prime} \text {. }
$$

For if $\left(d_{1}, d_{1}^{\prime}\right) \in S$, let $d_{1}=d_{2} d_{2}^{\prime}$ and $d_{1}^{\prime}=d_{3} d_{3}^{\prime}$ where $d_{2} d_{3}=d$ and $d_{2}^{\prime} d_{3}^{\prime}=d^{\prime}$. Then the following chain obtains:

$$
\begin{aligned}
\left(d d^{\prime}\right) & \longrightarrow\left(d_{1}, d_{1}^{\prime}\right) \longrightarrow\left(d_{2}, d_{2}^{\prime}, d_{1}^{\prime}\right) \longrightarrow\left(d_{2}, d_{2}^{\prime}, d_{3}, d_{3}^{\prime}\right) \\
\longrightarrow & \left(d_{2} d_{3}, d_{2}^{\prime} d_{3}^{\prime}\right)=\left(d, d^{\prime}\right) .
\end{aligned}
$$


Since $S$ is a closed set, it follows from this that $\left(d, d^{\prime}\right) \in S$, which is contrary to our assumption.

It follows that $g \in M(S)$ where $g$ is the function defined above. It is not hard to see that $\left[g^{*} 1\right](a b) \geqq 2$ but $\left[g^{*} 1\right](a)=1=\left[g^{*} 1\right](b)$, a contradiction.

Theorem 3.7. Let $S$ be a closed set. Then the following statements are equivalent.

(i) $S$ has property $P$,

(ii) $S$ has property $P^{\prime}$,

and

(iii) $S \subseteq \mathscr{R}$ and $S$ is divisible.

Proof. We have shown $(1) \Rightarrow(2) \Rightarrow(3)$. Let $f, g \in M(S)$ and $(a, b) \in S$. Then

$$
\begin{aligned}
{\left[f^{*} g\right](a b) } & =\sum_{d\left|a, d^{\prime}\right| b} f\left(d d^{\prime}\right) g\left(a / d b / d^{\prime}\right) \\
& =\sum_{d\left|a, d^{\prime}\right| b} f(d) f\left(d^{\prime}\right) g(a / d) g\left(b / d^{\prime}\right) \\
& =\sum_{d \mid a} f(d) g(a / d) \sum_{d^{\prime} \mid b} f\left(d^{\prime}\right) g\left(b / d^{\prime}\right) \\
& =\left[f^{*} g\right](a) \cdot\left[f^{*} g\right](b)
\end{aligned}
$$

Proof of Theorem 3.1. If $f \in M(S)$, then $f \in M\left(S^{*}\right)$. Hence, if $S$ has property $P$, then $S^{*}$ has property $P$. Therefore $S$ has property $P$ if and only if $S^{*}$ is a divisible subset of $\mathscr{R}$. In particular all divisible subsets of $\mathscr{R}$ have property $P$. It should be noted, however, that there exist examples of sets $S \subseteq \mathscr{R}$ which are not divisible but whose closures are divisible.

The function $E$ which has value 1 at 1 and 0 elsewhere is the identity under Dirichlet convolution. Therefore it is easy to see that a function $f$ has an inverse $\hat{f}$ if and only if $\hat{f}(1) \neq 0$, in which case, $\hat{f}(1)=1 / f(1)$, and $\hat{f}(n)=(-1 / f(1))\left(\sum_{d \mid n, d \neq n} \hat{f}(d) f(n / d)\right)$.

THEOREM 3.8. Let $S \subseteq N \times N$. Then $M(S)$ is a group if and only if $S \subseteq \mathscr{R},\{(1, n)\}_{n=1}^{\infty} \subseteq S$, and $S^{*}$ is a divisible set.

Proof. All that remains to show is that given $S \subseteq \mathscr{R}$, $\{(1, n)\}_{n=1}^{\infty} \subseteq S$, and $S^{*}$ divisible, then $f \in M(S)$ implies that $\hat{f} \in M(S)$. First, $f(1)=1$ so that $\hat{f}$ exists and $\hat{f}(n)=\hat{f}(1) \hat{f}(n)$. Let $(a, b) \in S$ and assume that $\left(d, d^{\prime}\right) \in T(\hat{f})$ for all $d\left|a, d^{\prime}\right| b$ and $d d^{\prime}<a b$. Then 


$$
\begin{aligned}
-\hat{f}(a b)= & \sum_{\substack{d\left|a, d^{\prime}\right| b \\
d d^{\prime} \neq a b}} \hat{f}\left(d d^{\prime}\right) f\left(a b / d d^{\prime}\right) \\
= & \sum \hat{f}(d) \hat{f}\left(d^{\prime}\right) f(a / d) f\left(b / d^{\prime}\right) \\
= & \sum_{d \mid a, d \neq a} \hat{f}(d) f(a / d) \cdot \sum_{d^{\prime} \mid b, d^{\prime} \neq b} \hat{f}\left(d^{\prime}\right) f\left(b / d^{\prime}\right) \\
& +\sum_{d \mid a, d \neq a} \hat{f}(d) f(a / d) \hat{f}(b)+\sum_{d^{\prime} \mid b, d^{\prime} \neq b} \hat{f}\left(d^{\prime}\right) f\left(b / d^{\prime}\right) \hat{f}(a) \\
= & (-\hat{f}(a) \hat{f}(b))+\hat{f}(b)(-\hat{f}(a))+\hat{f}(a)(-\hat{f}(b)) \\
= & -\hat{f}(a) \hat{f}(b) .
\end{aligned}
$$

This completes the proof.

\section{REFERENCES}

1. E. D. Cashwell and E. J. Everett, The ring of number-theoretic functions, Pacific J. Math., 9 (1959), 975-985.

2. D. L. Goldsmith, $A$ generalized convolution for arithmetic functions, Duke Math. J., 38, (1971), 279-283.

Received September 1971. Research supported in part by the National Science Foundation under grant GP-12015.

California State University, Humboldt 


\section{PACIFIC JOURNAL OF MATHEMATICS}

\section{EDITORS}

H. SAMELSON

Stanford University

Stanford, California 94305

C. R. Hовву

University of Washington

Seattle, Washington 98105
J. DugundJI

Department of Mathematics University of Southern California

Los Angeles, California 90007

RICHARD ARENS

University of California

Los Angeles, California 90024

\section{ASSOCIATE EDITORS}

E. F. BECKENBACH

B. H. NeumanN

F. WOLF

K. YoSHIDA

\section{SUPPORTING INSTITUTIONS}

UNIVERSITY OF BRITISH COLUMBIA

CALIFORNIA INSTITUTE OF TECHNOLOGY

UNIVERSITY OF CALIFORNIA

MONTANA STATE UNIVERSITY

UNIVERSITY OF NEVADA

NEW MEXICO STATE UNIVERSITY

OREGON STATE UNIVERSITY

UNIVERSITY OF OREGON

OSAKA UNIVERSITY
UNIVERSITY OF SOUTHERN CALIFORNIA

STANFORD UNIVERSITY

UNIVERSITY OF TOKYO

UNIVERSITY OF UTAH

WASHINGTON STATE UNIVERSITY

UNIVERSITY OF WASHINGTON

AMERICAN MATHEMATICAL SOCIETY

NAVAL WEAPONS CENTER

Printed in Japan by International Academic Printing Co., Ltd., Tokyo, Japan 


\section{Pacific Journal of Mathematics}

\section{Vol. 44, No. $1 \quad$ May, 1973}

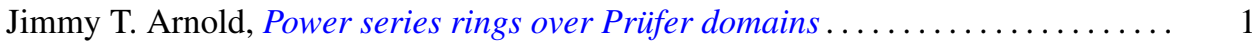

Maynard G. Arsove, On the behavior of Pincherle basis functions . . . . . . . . . 13

Jan William Auer, Fiber integration in smooth bundles ................. 33

George Bachman, Edward Beckenstein and Lawrence Narici, Function algebras

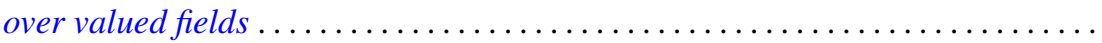

Gerald A. Beer, The index of convexity and the visibility function . . . . . . . . . . .

James Robert Boone, A note on mesocompact and sequentially mesocompact

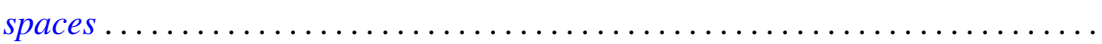

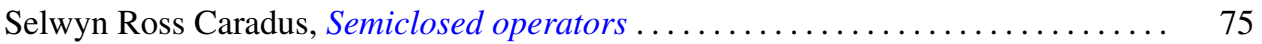

John H. E. Cohn, Two primary factor inequalities . . . . . . . . . . . . . . . 81

Mani Gagrat and Somashekhar Amrith Naimpally, Proximity approach to

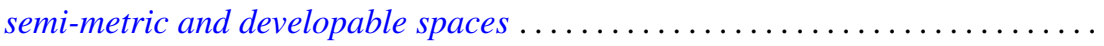

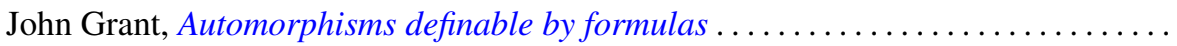

Walter Kurt Hayman, Differential inequalities and local valency ..............

Wolfgang H. Heil, Testing 3-manifolds for projective planes . . . . . . . . . . . . .

107

Melvin Hochster and Louis Jackson Ratliff, Jr., Five theorems on Macaulay

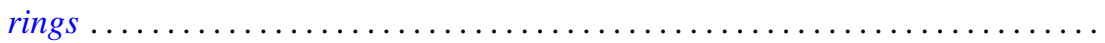

Thomas Benton Hoover, Operator algebras with reducing invariant subspaces ....

James Edgar Keesling, Topological groups whose underlying spaces are separable

Fréchet manifolds...

Frank Leroy Knowles, Idempotents in the boundary of a Lie group . .

191

George Edward Lang, The evaluation map and EHP sequences ...

201

Everette Lee May, Jr, Localizing the spectrum . . . . . . . . . . . .

211

Frank Belsley Miles, Existence of special $K$-sets in certain locally compact abelian groups.

Susan Montgomery, A generalization of a theorem of Jacobson. II . .

T. S. Motzkin and J. L. Walsh, Equilibrium of inverse-distance forces in

three-dimensions.

Arunava Mukherjea and Nicolas A. Tserpes, Invariant measures and the converse

of Haar's theorem on semitopological semigroups .

James Waring Noonan, On close-to-convex functions of order $\beta$

Donald Steven Passman, The Jacobian of a growth transformation

Dean Blackburn Priest, A mean Stieltjes type integral ........ .

Joe Bill Rhodes, Decomposition of semilattices with applications to topological

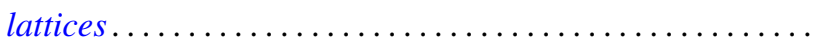

Claus M. Ringel, Socle conditions for $\mathrm{QF}-1$ rings ..........

Richard Rochberg, Linear maps of the disk algebra

Roy W. Ryden, Groups of arithmetic functions under Dirichlet convolution . .

Michael J. Sharpe, A class of operators on excessive functions

Erling Stormer, Automorphisms and equivalence in von Neumann algebras ..

Philip C. Tonne, Matrix representations for linear transformations on series

analytic in the unit disc. 